\title{
TESES
}

\section{A EPIDEMIOLOGIA E O PROJETO EMANCIPADOR NAS PRÁTICAS DE SAÚDE: A CRÍTICA DA RAZÃO INSTRUMENTAL NA CONSTITUIÇÃO HISTÓRICA DA CIÊNCIA EPIDEMIOLÓGICA}

O estudo trata das relações entre estrutura epistemológica da epidemiologia e formas de organização social das práticas de saúde. Trata-se de um estudo crítico acerca dos alcances e limitações da ciência epidemiológica diante das necessidades de saúde concretamente postas no plano coletivo. A questão teórica central é relativa à consubstancialidade tecno-social da determinação destes alcances e limitações, expressa na historicidade do modo como se estrutura a apreensão objetiva e explicação racional dos fenômenos coletivos de saúde e doença.

Nesse sentido, são examinados os marcos conceituais da trajetória de constituição de um objeto de saber propriamente epidemiológico, referidos à racionalidade mais ampla da produção social, de um modo geral, procurando perscrutá-los quanto às suas reper'cussões práticas concretas.

Ressalta-se a necessidade de superação do caráter auto-instruído da produção de conhecimento na epidemiologia, resgatando reflexiva e dinamicamente na estruturação epistemológica desta ciência a historicidade de seu objeto, a fim de que se possa expandir a compreensão ontogenética do processo saúde-doença e favorecer o potencial emancipador das práticas de saúde coletiva.

José Ricardo de C. Mesquita Ayres Dissertação de mestrado, 1991

Centro de Saúde Escola Samuel B. Pessoa Departamento de Medicina Preventiva Faculdade de Medicina da USP Av. Vital Brasil, 1490 - Butantã São Paulo — SP CEP 05503-000

\section{O CONHECIMENTO EPIDEMIOLÓGICO NA ORGANIZAÇÃO TECNOLÓGICA DO CONTROLE DA MALÁRIA: SÃO PAULO, 1930-90}

As condiçôes de produção da malária e a organização tecnológica para seu controle, no Estado de São Paulo, entre 1930 e 1990, são estudadas através da construção de modelos que buscam reunir a estrutura de necessidades de saúde, o saber que recorta e constrói o objeto para o trabalho, a organização tecnológica e o produto do trabalho em três períodos distintos.

No primeiro período, de 1930 a 1950, prevalece o modelo ecológico-ambientalista, segundo o qual a malária é compreendida como um problema local complexo, determinado por inúmeras variáveis, dentre as quais as ambientais detêm o maior peso. O controle volta-se para a redução e destruição dos criadouros de anofelinos, através de modificações ambientais. A necessidade socialmente posta é identificada com a redução da capacidade produtiva dos trabalhadores rurais ou daqueles envolvidos na construção de obras de infra-estrutura econômica e o atendimento a ela é definido a partir da relevância econômica.

No segundo período, de 1950 a 1970, passa-se para o modelo técnico-campanhista: a doença é reduzida a seus traços genéricos e comuns e busca-se sua erradicação através da estratégia da campanha. A necessidade em relação à doença é expressa pela taxa de incidência média abrangendo todos os membros da população, sem distinções.

No terceiro período, de 1970 a 1990, constrói-se outro modelo, o focal preventivista, segundo o qual a malária é vista com um doeça focal ligada a circunstâncias particulares e seu controle deve basear-se em medidas preventivas dirigidas principalmente aos homens expostos. A necessidade social é então 
assimilada ao risco de reintrodução da transmissão.

Finalmente, são consideradas as perspectivas para a década de 1990 , a partir da nova estratégia definida pela Organização Mundial de Saúde (OMS), em 1992, segundo a qual o enfoque de risco, para grupos de indivíduos, se sobrepõe ao enfoque de saúde coletiva.

\author{
Rita Barradas Barata \\ Dissertação de doutoramento, 1992 \\ Departamento de Medicina Social \\ Faculdade de Ciências Médicas da Santa Casa \\ Rua Dr. Cesário Motta Jr., 112 \\ São Paulo — SP CEP 01221-220
}

\section{ESTRUTURAÇÃO E \\ TRANSFORMAÇÃO DA PRÁTICA MÉDICA: ESTUDO DE \\ ALGUMAS DAS CARACTERÍSTICAS \\ DO MODELO DE TRABALHO NA \\ SEGUNDA METADE DO SÉCULO XIX E INÍCIO DO XX}

O presente estudo trata de algumas características da configuração do trabalho médico. A partir do conceito de 'modelo de trabalho médico' foi possível evidenciar certas peculiaridades da prática médica em duas dimensões complementares: a articulação entre seus elementos nucleares de operação - concepção de doença, forma de elaboração do diagnóstico e orientação terapêutica; e as vinculações do trabalho à produção e incorporação de conhecimentos científicos, inseridos nas condições históricas e sociais concretas. Como material empírico, foram utilizados tratados médicos consagrados por sua relevância e difusão, e analisando-se as orientações neles apresentadas para o trabalho com duas doenças-índice: a pneumonia e a nefrite.

A comparação entre o conteúdo dos diversos tratados mostra a perspectiva de conformação do trabalho médico no período não como mera transformação linear e progressiva, mas como movimento processual, resultante de múltiplas e, muitas vezes, contraditórias determinações, não se podendo afirmar que ele se cristaliza como um modelo acabado.

\author{
Ana Silvia Whitaker Dalmaso \\ Dissertação de mestrado, 1991 \\ Centro de Saúde Escola Samuel B. Pessoa \\ Departamento de Medicina Preventiva \\ Faculdade de Medicina da USP \\ Av. Vital Brasil, 1490 - Butantã \\ São Paulo - SP CEP 05503-000
}

\section{POLÍtica de CONTROLE DA AIDS \\ DA SECRETARIA DE ESTADO DA \\ SAÚde de SÃo PAULO, 1983-92: A HISTÓRIA CONTADA POR SEUS AGENTES}

O estudo relata a historiografia das propostas de ação da Secretaria de Estado da Saúde de São Paulo (Sessp), no período 1983-92, em resposta às necessidades de atenção à saúde, expressas pela população, em decorrência do aparecimento da Aids. Seu objetivo é apresentar as intencionalidades técnico-políticas desta instituição em termos de uma política sanitária no seu enfrentamento dessa questão, não pretendendo analisar as práticas operadas pela Sessp. Entrevistou-se os principais agentes institucionais envolvidos nessa história, resgatada através de depoimentos orais, documentos oficiais e oficiosos e amplo acervo jornalístico.

Os dados mostram conjunturas diferentes ao longo do tempo, de acordo com a relação mantida com a sociedade e com a racionalidade que presidiu suas práticas. Esta fundamentou-se na epidemiologia apenas na fase inicial de implantação do programa de controle da Aids, apesar de ser esse o saber que permite um 'discurso competente' sobre a saúde coletiva. Na quase totalidade do período estudado, seu modo operatório foi executado de forma internamente desarticulada, modulado por situações contingenciais e por demandas veiculadas pela mídia. Este modo de operar, caracterizado pelo pronto atendimento como primeira e única ação, encontra- 
va-se em sua fase de consolidação na rede pública estadual, após mudanças que resultaram no abandono do modelo tecnológico das programações, no bojo de movimentos mais amplos visando à expansão da cobertura assistencial. O relacionamento da instituição com usuários de seus serviços, sociedade em geral e os técnicos envolvidos na assistência ao paciente não permitiu a participação destes na formulação das políticas implementadas. A mídia - particularmente a imprensa - foi o canal escolhido por estes para se expressarem. A Sessp atuou através de técnicos nomeados como coordenadores de programa, os formuladores de políticas para a área, e criou instâncias assessoras de caráter científico, quase totalmente compostas por especialistas da academia. A complexidade da questão relativa à moralidade, cultura e possibilidades concretas de cidadania das populações dificultou o equacionamento do problema, como também o fez a crise geral da medicina.

A instituição acolheu a questão da Aids como pertinente à sua esfera de ação, reconhecendo a saúde como um direito da população. Porém, sua vontade política foi variável no período e ela não conseguiu estabelecer uma tradução tecnológica dessa vontade política, numa conjuntura de crise do modelo assistencial prevalente.

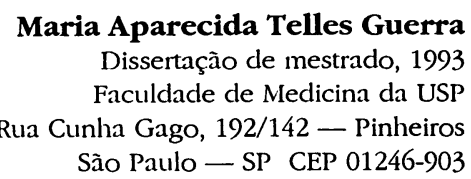

\section{A haNSEníase e AS PRÁticas SANITÁRIAS EM SÃO PAULO: DEZ ANOS DE SUBPROGRAMA DE CONTROLE DA HANSENÍASE NA SECRETARIA DE ESTADO DA SAÚDE, 1977-87}

O estudo trata da organização do trabalho nos centros de saúde da rede institucional da Sessp, considerando em especial as práticas referidas ao controle da hanseníase entre 1977 e 1987.

Partiu-se do princípio teórico de que as práticas de saúde são social e historicamente articuladas. Tomou-se então a organização do trabalho relativo ao controle da hanseníase enquanto organização capaz de reproduzir, no interior do trabalho, as relações sociais que se estabelecem nos processos históricos mais gerais da sociedade brasileira e mais específicos do Estado de São Paulo. Buscouse, assim, apreender de que modo o trabalho desenvolvido no subprograma de controle da hanseníase estruturou-se sob características dadas pela programação - forma proposta e implementada de organização da prática sanitária nos centros de saúde da rede estadual de São Paulo na década de 1970 - e simultaneamente pela articulação do setor de saúde na sociedade brasileira. Procurou-se também, entendendo a constituição da programação como um momento histórico específico da prática sanitária em São Paulo, estudar a programação reconstituindo a própria história das práticas de controle da hanseníase em São Paulo.

Fundamentou-se o estudo no conceito de modelo de organização tecnológica do trabalho como quadro teórico de análise das formas de organização dos processos de trabalho nos serviços de saúde, tomando-se a partir desse referencial, enquanto tipos abstratos polares, os modelos presididos pelos saberes reunidos no pólo de conceituação da epidemiologia e no pólo de conceituação da clínica. Assim, tanto a recuperação histórica das práticas de controle da hanseníase como a análise de suas características no período 1977-87 foi realizada buscando-se identificar a organização tecnológica concretamente operada.

Elegeram-se, como indicadores preferenciais da organização tecnológica do trabalho no subprograma de controle da hanseníase, o uso das práticas de avalização enquanto instrumentos de trabalho e o desempenho do conjunto de atividades reunidas no componente epidemiológico do subprograma.

A investigação empírica baseou-se na análise das informações quantitativas e qualitativas re- 
gistradas e disponíveis sobre o subprograma de controle da hanseníase no nível central da Secretaria da Saúde. Procurou-se identificar os momentos de maior aproximação ou distanciamento da prática relativa à hanseníase dos modelos de organização tecnológica pensados.

\section{Maria Inês Baptistella Nemes \\ Dissertação de mestrado, 1989 \\ Departamento de Medicina Preventiva Faculdade de Medicina da USP \\ Av. Dr. Arnaldo, $455 / 2^{\circ}$ - Cerqueira César São Paulo - SP CEP 01246-903}

\section{EPIDEMIA E CULTURA:}

\section{A AIDS E O MUNDO SECURITÁRIO}

Esta dissertação versa sobre determinados aspectos das epidemias, referidos a uma dimensão cultural, que correspondem aos modos como são vivenciadas as manifestações coletivas de doenças. Motiva-se especialmente pela importância que essa dimensão vem adquirindo na presente epidemia de Aids. Situa-se num nível de discussão preliminar, traçando um plano geral para problemas que possam vir a ser explorados em incursões empíricas e teóricas mais específicas. A dimensão cultural aqui trabalhada é tecida no entrecruzamento de processos estéticos e éticos.

A partir de uma aproximação semiótica de algumas imagens culturais da epidemia, são estabelecidos dois esquemas epidêmicos epidemia de contágio e epidemia irradiada - enquanto duas formas gerais do mesmo fenômeno, que podem ser identificadas no processo de gênese das concepções culturais modernas sobre contágio e epidemia, dois grandes modelos históricos da epidemia que se sucederam.

Ao se integrar o estudo dessa mutação na forma geral do fenômeno a uma análise dos processos éticos em curso, aponta-se para a construção de um conceito: securitarismo. Este conceito busca dar conta de um certo devir ético da cultura contemporânea, que. é igualmente apreensível nos esquemas estéticos. É no quadro de uma cultura securitária que se buscará dar inteligibilidade a alguns comportamentos culturais observados na presente epidemia de Aids.

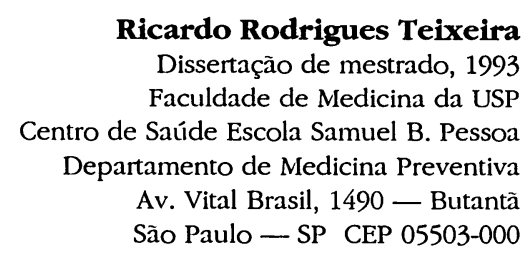

